\title{
Extreme pulmonary hypertension caused by mitral valve disease Natural history and results of surgery
}

\author{
C. Ward and B. W. Hancock \\ From the Cardio-Thoracic Unit, Northern General Hospital, Sheffield
}

Five hundred and eighty six patients with mitral valve disease were studied with cardiac catheterization between 1961 and 1972; $48(8.2 \%)$ had extreme pulmonary hypertension (resting systolic pulmonary artery pressure of $80 \mathrm{mmHg}$ or above and pulmonary vascular resistance of ro units or greater) and of these patients, 27 underwent cardiac surgery. The operative mortality for mitral valvotomy was II per cent and for mitral valve replacement 56 per cent. The overall mortality was 31 per cent. The risks of operation were increased in those with a long history of cardiac symptoms, those over 50 years of age, and in the presence of associated aortic valve disease. The mean survival for those patients not having operation was only $2.4 \pm 0.5$ years. The mean follow-up period for those surviving operation has been $5.8 \pm 0.6$ years, and symptomatic improvement has been good.

The operations of mitral valvotomy and mitral valve replacement have greatly improved the prognosis of patients with mitral valve disease. It is generally recognized that patients with severe pulmonary hypertension are less likely to survive such operations (Emanuel and Ross, 1967). Despite this, it has been suggested, because of the potential benefits, that patients in this situation should not be refused surgery (Hamer et al., 1968). Barclay et al. (1972) considered a systolic pulmonary artery pressure of Iro $\mathrm{mmHg}$ or greater to be an absolute contraindication to mitral valve replacement. The increased risk of operation in these patients can only be justified if the prognosis is thereby improved. We have, however, been unable to find any report which specifically outlines the natural history of extreme pulmonary hypertension caused by mitral valve disease and reports of mitral valve surgery on such patients do not indicate the expected course of the disease in a comparable group not having surgery. The objectives of this study have been to outline the natural history of extreme pulmonary hypertension secondary to mitral valve disease, to determine the risks of surgery in such patients, and to discover if there is a group of patients in whom the risks of operation are not justified.

Received 28 May 1974.

\section{Patients and methods}

Case records from the Cardio-Thoracic Unit of the Northern General Hospital, Sheffield have been examined for the years 196I to 1972 . Data on 586 patients with a principal diagnosis of mitral valve disease, who had had cardiac catheterization, were studied. Fortyeight patients had extreme pulmonary hypertension defined arbitrarily as a resting pulmonary artery systolic pressure equal to, or greater than, $80 \mathrm{mmHg}$. Details of the following were noted: pulmonary artery pressure; wedged pulmonary artery pressure (indirect left atrial pressure); electrocardiographic evidence of atrial fibrillation and of left and/or right ventricular hypertrophy; $x$-ray evidence of cardiomegaly, left atrial enlargement, and pulmonary hypertension; presence of mitral valve calcification; relevant medical history; and the nature of valve lesions. An estimate of pulmonary vascular resistance was made on the basis of Wood's findings (1954), who showed that it was linearly related to the pulmonary pressure gradient (mean pulmonary artery pressure - mean left atrial pressure); a pulmonary vascular resistance of 6 to to units occurring in those patients with a pulmonary pressure gradient of 15 to $30 \mathrm{~mm}$ and a pulmonary vascular resistance of to to 30 units with a pulmonary pressure gradient of 30 to $70 \mathrm{~mm}$.

The New York Heart Association functional classification has been used in the clinical assessment of the patients.

Cardiac catheterization had been performed on each patient as a preliminary to consideration for surgery. 
Those patients who were not operated on after cardiac catheterization were classed as the 'nonoperated' group (group I). Those who underwent operation were classed as the 'surgical' group (group 2). The latter (group 2) was further subdivided into those who survived the postoperative period (group $2 \mathrm{~A}$ ) and those who did not (group 2B).

The findings in these groups are summarized in Tables $I$ and 2. Statistical significance has been assessed from values for probability $(P)$ based on Students' t-test or $\chi^{2}$ test.

\section{Results}

\section{All patients}

Of the total of 48 patients, I 5 had a pulmonary arterial systolic pressure of 80 to $89 \mathrm{mmHg}, 9$ of 90 to 99 $\mathrm{mmHg}, 12$ of 100 to $109 \mathrm{mmHg}$, and 12 of greater than IIO $\mathrm{mmHg}$. In 3 patients, the pulmonary arterial pressure was greater than $150 \mathrm{mmHg}$. The pulmonary vascular resistance was Io to 15 units in 26 patients $(54 \%)$ and greater than 15 units in 22 patients $(46 \%)$.

\section{Group r: no operation}

This group consisted of 21 patients ( 12 female and 9 male). At the time of catheterization the mean age was $46 \cdot 2 \pm I \cdot 7$ years and the length of history $7 \cdot 4 \pm I \cdot I$ years. At that time I patient was in functional class II, I4 were in class III, and 6 in class IV. Seven patients had additional significant aortic valve disease. Only 6 patients had isolated mitral stenosis. The remainder had additional mitral regurgitation and/or aortic valve disease. Two patients have survived (both in functional class IV) one for 6 years and the other for 4 years.

\section{Group 2: all surgical patients}

In all, 27 patients ( 19 women and 8 men) underwent 29 operations. At the time of catheterization the mean age was $42.4 \pm I .6$ years and length of history $5 \cdot 6 \pm I \cdot 3$ years. Two patients were in functional class II, I9 in class III, and 6 in class IV. Eighteen patients had mitral valvotomy ( $I$ with additional aortic valve replacement). Nine had mitral valve replacement and 2 mitral plus aortic valve replacement.

\section{Group 2A: patients surviving surgery}

Nineteen patients ( 16 female and 3 male) survived 20 operations. The mean age at the time of cardiac catheterization was $40 \cdot 4 \pm \mathrm{I} \cdot 3$ years. At this stage,

TABLE I Comparison of results in nonoperated and surgical groups

\begin{tabular}{|c|c|c|c|}
\hline & $\begin{array}{l}\text { Group I } \\
\text { Patients not having } \\
\text { surgery (2I patients) }\end{array}$ & $\begin{array}{l}\text { Group } 2 \\
\text { Patients having surgery } \\
\text { after catheter studies } \\
\text { (27 patients, } 29 \\
\text { operations) }\end{array}$ & $\begin{array}{l}\text { Statistical } \\
\text { difference } \\
(P)\end{array}$ \\
\hline $\begin{array}{l}\text { Mean age ( } \pm \text { SE mean) at time of catheter } \\
\text { assessment }(y r)\end{array}$ & $46 \cdot 2( \pm r \cdot 7)$ & $42 \cdot 4( \pm I \cdot 6)$ & $>0 \cdot 10$ \\
\hline $\begin{array}{l}\text { Sex: } \text { Male } \\
\text { Female }\end{array}$ & $\begin{array}{r}9(43 \%) \\
12(57 \%)\end{array}$ & $\begin{array}{r}8(29 \%) \\
19(71 \%)\end{array}$ & \\
\hline Mean length of history (yr) ( \pm SE mean) & $7 \cdot 4( \pm I \cdot I)$ & $5 \cdot 6( \pm 1 \cdot 3)$ & $>0 \cdot 10$ \\
\hline $\begin{array}{l}\text { Electrocardiogram AF (no. of cases and percentage } \\
\text { of total) }\end{array}$ & $13(62 \%)$ & $19(70 \%)$ & $>0.10$ \\
\hline $\begin{array}{l}\text { Chest } x \text {-ray, cardiothoracic ratio }>50 \% \text { (no. of } \\
\text { cases and percentage of total) }\end{array}$ & $20(95 \%)$ & $26(89 \%)$ & $>0 \cdot 10$ \\
\hline $\begin{array}{l}\text { Pulmonary artery pressure }(\mathrm{mmHg})(\text { mean } \pm \mathrm{SE} \\
\text { mean) }\end{array}$ & $\frac{105 \pm 5 \cdot 2}{47 \cdot 5 \pm 3 \cdot 7}$ & $\frac{96 \cdot 6 \pm 3 \cdot 4}{44 \cdot 4 \pm 2 \cdot 6}$ & $>0 \cdot 10$ \\
\hline Left atrial pressure $(\mathrm{mmHg})($ mean $\pm \mathrm{SE}$ mean) & $\frac{40 \cdot 3 \pm 2 \cdot 9}{20 \cdot 5 \pm 1 \cdot 5}$ & $\frac{42 \cdot 5 \pm 2 \cdot 4}{23 \cdot 1 \pm 1 \cdot 4}$ & $>0 \cdot 10$ \\
\hline $\begin{array}{l}\text { Mitral valve calcification (no. of cases and per- } \\
\text { centage of total) }\end{array}$ & II $(55 \%)$ & $13(45 \%)$ & $>0.10$ \\
\hline $\begin{array}{l}\text { Valve lesions (no. } \\
\text { of cases and } \\
\text { percentage of } \\
\text { total) }\end{array} \quad\left\{\begin{array}{l}\text { Predominant mitral stenosis } \\
\text { Mixed mitral disease } \\
\text { Mitral and aortic valve disease }\end{array}\right.$ & $\begin{array}{l}6(29 \%) \\
8(38 \%) \\
7(33 \%)\end{array}$ & $\begin{array}{r}18(62 \%) \\
8(28 \%) \\
3(10 \%)\end{array}$ & $\begin{array}{l}<0.05 \\
>0.10 \\
<0.05\end{array}$ \\
\hline
\end{tabular}

$\mathrm{AF}=$ Atrial fibrillation 
TABLE 2 Comparison of results in survivors and patients dying in postoperative period

\begin{tabular}{|c|c|c|c|c|}
\hline & & $\begin{array}{l}\text { Group } 2 A \\
\text { Patients surviving } \\
\text { operation: ( } 19 \text { patients, } \\
20 \text { operations) }\end{array}$ & $\begin{array}{l}\text { Group } 2 B \\
\text { Patients dying during } \\
\text { operation or within } \\
3 \text { wk of operation } \\
\text { ( } 9 \text { patients) }\end{array}$ & $\begin{array}{l}\text { Statistical } \\
\text { difference } \\
(P)\end{array}$ \\
\hline \multicolumn{2}{|c|}{ Mean age ( \pm SE mean) at time of surgery $(y r)$} & $40 \cdot 4 \pm I \cdot 3$ & $47 \cdot 1 \pm 3 \cdot 8$ & $<0 \cdot 1$ \\
\hline \multicolumn{2}{|c|}{$\begin{array}{l}\text { Sex: Male } \\
\text { Female }\end{array}$} & $\begin{array}{r}3(16 \%) \\
16(84 \%)\end{array}$ & $\begin{array}{l}6(67 \%) \\
3(33 \%)\end{array}$ & \\
\hline \multicolumn{2}{|c|}{ Mean length of history $(y r)$ ( \pm SE mean) } & $4.2 \pm 0.8$ & $9 \cdot 3 \pm 2 \cdot 1$ & $<0.05$ \\
\hline \multicolumn{2}{|c|}{ Electrocardiogram AF (no. of cases and \% of total) } & II $(55 \%)$ & $8(89 \%)$ & $<0 \cdot 1$ \\
\hline \multicolumn{2}{|c|}{$\begin{array}{l}\text { Chest } x \text {-ray, cardiothoracic ratio }>50 \% \text { (no. of } \\
\text { cases and } \% \text { of total) }\end{array}$} & I7 $(85 \%)$ & $9(100 \%)$ & $>0.1$ \\
\hline \multicolumn{2}{|c|}{$\begin{array}{l}\text { Pulmonary artery pressure }(\mathrm{mmHg})(\text { mean } \pm \mathrm{SE} \\
\text { mean) }\end{array}$} & $\frac{94 \cdot 5 \pm 3 \cdot 6}{43 \cdot 8 \pm 3 \cdot 4}$ & $\frac{101 \pm 7 \cdot 8}{42 \cdot 5 \pm 2 \cdot 5}$ & $>0.1$ \\
\hline \multicolumn{2}{|c|}{ Left atrial pressure $(\mathrm{mmHg})($ mean $\pm \mathrm{SE}$ mean $)$} & $\frac{42 \cdot 8 \pm 2 \cdot 3}{23 \cdot 4 \pm 2 \cdot 5}$ & $\frac{41 \cdot 8 \pm 5 \cdot 2}{23 \cdot 8 \pm 3 \cdot 8}$ & $>0.1$ \\
\hline \multicolumn{2}{|c|}{$\begin{array}{l}\text { Mitral valve calcification (no. of cases and } \% \text { of } \\
\text { total) }\end{array}$} & $6(30 \%)$ & $7(78 \%)$ & $<0.05$ \\
\hline $\begin{array}{l}\text { Valve lesions (no. } \\
\text { of cases and \% } \\
\text { of total) }\end{array}$ & $\begin{array}{l}\text { Predominant mitral stenosis } \\
\text { Mixed mitral disease } \\
\text { Mitral and aortic valve disease }\end{array}$ & $\begin{array}{l}\text { I5 }(75 \%) \\
4(20 \%) \\
\text { I }(5 \%)\end{array}$ & $\begin{array}{l}3(33 \%) \\
4(44 \%) \\
2(22 \%)\end{array}$ & $\begin{array}{l}<0.05 \\
>0.1 \\
>0.1\end{array}$ \\
\hline $\begin{array}{l}\text { Valve surgery (no. } \\
\text { of cases and \% } \\
\text { of total) }\end{array}$ & $\begin{array}{l}\text { Mitral valvotomy } \\
\text { Mitral valve replacement } \\
\text { Aortic valve replacement }+ \\
\text { mitral valvotomy } \\
\text { Double valve replacement }\end{array}$ & $\begin{array}{l}\text { I5 }(75 \%) \\
4(20 \%) \\
\text { I }(5 \%) \\
-\end{array}$ & $\begin{array}{l}2(22 \%) \\
5(56 \%) \\
- \\
2(22 \%)\end{array}$ & $\begin{array}{l}<0.05 \\
<0.1\end{array}$ \\
\hline
\end{tabular}

I patient was in functional class II, 13 in class III, and 5 in class IV. The length of history was $4.2 \pm$ 0.8 years. The operation was mitral valvotomy in 15 patients, mitral valvotomy plus aortic valve replacement in $I$, and mitral valve replacement in 4. Fifteen patients are alive at the time of writing (mean follow-up period $5.8 \pm 0.6$ years). There have been 4 late deaths - I from bronchiolitis, I after a road traffic accident, I with congestive cardiac failure 6 years after operation, and I after further cardiac surgery. Of the survivors, 3 are in functional class $I, I I$ in class II, and I in class III.

\section{Group 2B: patients dying in postoperative period}

There were $9^{1}$ postoperative deaths ( 3 female and 6 male). The mean age at the time of cardiac catheterization was $47 \cdot 1 \pm 3.8$ years and length of history $9 \cdot 3 \pm 2 \cdot I$ years. At this stage I patient was in functional class II, 7 in class III, and $I$ in class IV. Of the 6 patients aged 50 years and over at the time of surgery, 5 died postoperatively. Of the 9 patients, 5 had mitral valve replacement and 2 mitral valvotomy. Both patients who had mitral plus aortic valve replacement died after operation. The inci-

1 One male patient died after second operation. dence of mitral valve calcification and atrial fibrillation was significantly increased in this group compared with the surgical survivor group.

\section{Discussion}

Extreme pulmonary hypertension secondary to mitral valve disease has a poor prognosis, and though surgery is more hazardous in these patients than in those with lower pulmonary artery pressures, the potential benefits appear to justify the risks in the majority of patients.

Olesen (1962) has shown in a purely clinical study that the prognosis for medically treated patients with mitral valve disease is worse when there is clinical evidence of increasing pulmonary hypertension. Ten (48\%) of 21 patients in our series who did not have surgery died within a year of cardiac catheterization. This group, however, is not strictly comparable with the surgical group because of the more common additional presence of aortic valve disease. The mean survival of those patients with associated aortic valve disease was I. $5 \pm 0.9$ years. Even without this high risk group, the mean survival of the remaining 14 patients was only $2.9 \pm 0.6$ years. The reasons for not operating on patients after cardiac catheterization were not 
always made clear in the case records but may be surmised. Many of the patients were from the earlier years of the study when surgeons were less inclined to operate on high risk patients, particularly as many of these patients would have needed mitral valve or double valve replacement operations which were not then being routinely performed.

Mitral valvotomy and mitral valve replacement have dramatically improved the outlook for many patients with mitral valve disease (Emanuel, 1963; Hamer et al., 1968). Nichols et al. (1964) reported on an overall surgical mortality for all types of mitral valve surgery, of 8 per cent increasing to 23 per cent for those with a pulmonary arterial pressure greater than $50 \mathrm{mmHg}$. Hamer et al. (1968), reporting on their earliest mitral valve replacements, noted a mortality of 25 per cent which rose to 35 per cent in patients with a pulmonary vascular resistance greater than to units. Three out of four of their patients with a pulmonary vascular resistance in excess of $\mathrm{I} 4$ units died after operation.

It has been suggested that other factors increase the hazards of operation (Turner, 1967). In the present study, atrial fibrillation, mitral valve calcification, and a long history of symptoms were more common in those who died after operation than in those who survived. These patients were also older than the survivors. The situation is complicated by the frequent occurrence of these factors in combination in the same patient, making it difficult to assess the part played by any one of them in affecting the prognosis. Emanuel (1963) has helped to clarify the situation. The mortality for his patients undergoing mitral valvotomy who had a pulmonary vascular resistance of 10 units or greater was 13 per cent, this figure rising to 26 per cent if there was mitral valve calcification and to 50 per cent with the additional presence of mitral regurgitation. Most reported series relate mortality primarily to the level of pulmonary hypertension, and in interpreting results it must be remembered that other factors are contributing, though to what extent is not always clear.

Patients in this study who underwent surgery, all had a pulmonary vascular resistance of greater than Io units, and in 13 it was greater than 15 units. The overall operative mortality was 3 I per cent, II per cent for mitral valvotomy and 56 per cent for mitral valve replacement. Five patients died after mitral valve replacement. The pulmonary arterial pressure and pulmonary vascular resistance in these patients was not significantly different from that recorded in the survivors. It was noted that no patient over the age of 45 years survived mitral valve replacement; the duration of symptoms in those patients who died after operation was longer than in the sur- vivors (mean $9 \cdot 3 \pm 2 \cdot 1$ years, as opposed to $4 \cdot 2 \pm 0 \cdot 8$ years) and men were less likely to survive than women. The 4 who had survived mitral valve replacement are alive $1 \frac{1}{2}, 2,2 \frac{1}{2}$, and 4 years, respectively, after operation. The mean survival for all surgical patients surviving operation has been $5.8 \pm 0.6$ years. For the medically treated group, even excluding those with additional aortic valve disease, the mean survival has been only $2 \cdot 9 \pm 0.6$ years. Symptomatic improvement in those who survive operation is also obvious. At the time of cardiac catheterization, $3 I$ patients were in functional class III and I2 in class IV. The 2 patients in the medically treated group, alive at the time of writing 4 and 6 years after investigations, are in functional class IV. The other members of this group remained severely incapacitated until they died. Fifteen patients from the surgical group are alive, I4 of these being in functional classes I and II. The 4 patients who survived mitral valve replacement were in class II when last seen.

The poor prognosis for patients who do not have operation has not previously been sufficiently stressed. A quarter of the patients in our study died within 6 months of cardiac catheterization and a half within 12 months.

Extreme pulmonary hypertension has been considered a relative, if not absolute, contraindication to valve surgery particularly in those requiring mitral valve replacement. The findings presented here suggest that the reverse should be the case. Extreme pulmonary hypertension should be regarded as a positive indication for early operation in many of these patients. No patient should be refused mitral valvotomy because of extreme pulmonary hypertension, neither should most patients under the age of perhaps 50 to 55 years be refused mitral valve replacement. However, patients older than this, those with a very long history of breathlessness, and those needing additional aortic valve replacement remain a serious problem and surgery still has a very high mortality in such patients. It is likely that a group of such patients exists in whom the risks of operation are still not justifiable. It is anticipated that this group will steadily diminish as postoperative care improves.

We are grateful to the physicians and surgeons of the Cardio-Thoracic Unit, Sheffield, for allowing us to report details of the patients and to Professor A. M. Walker for help with statistical analysis.

\section{References}

Barclay, R. S., Reid, J. M., Stevenson, J. G., Welsh, T. M., and McSwan, N. (1972). Long-term follow-up of mitral valve replacement with Starr-Edwards prostheses. British Heart fournal, 34, 129. 
Emanuel, R. (1963). Valvotomy in mitral stenosis with extreme pulmonary vascular resistance. British Heart fournal, 25, II9.

Emanuel, R., and Ross, K. (1967). Pulmonary hypertension in rheumatic heart disease. Progress in Cardiovascular Diseases, 9, 40r.

Hamer, J., Boulton, T., Fleming, J., Hayward, G. W., Hill, I. M., Monro, I., Simon, G., and Tubbs, C. S. (I968). Mitral valve replacement: long-term results with particular reference to changes in pulmonary vascular resistance. Thorax, 23, I.

Nichols, H. T., Raber, G. T., Blanco, G., Adam, A., and Morse, D. P. (1964). Results of mitral valvular surgery in patients with severe pulmonary hypertension. Circulation, 30, Suppl. 3, 132.

Olesen, K. H. (I962). The natural history of 27 I patients with mitral stenosis under medical treatment. British Heart fournal, 24, 349.

Turner, R. W. D. (1967). Surgery of the mitral valve. British Heart fournal, 29, 641.

Wood, P. (1954). An appreciation of mitral stenosis. Part II. Investigations and results. British Medical fournal, I, II I 3 .

Requests for reprints to Dr. C. Ward, Northern General Hospital, Sheffield S5 7AU. 